\title{
REPORT ON THE 20TH INTERNATIONAL RADIOCARBON CONFERENCE GRAPHITIZATION WORKSHOP
}

\author{
Jocelyn Turnbull ${ }^{1}$ Christine Prior $^{2}$ - Graphitization Workshop Participants
}

ABSTRACT. A sample preparation workshop was convened at the 20th International Radiocarbon conference, with about 30-40 attendees. The term "sample preparation" was not further specified to allow participants to address the laboratory issues most important to them. Given the short time available, the focus quickly narrowed to details of graphite preparation for accelerator mass spectrometry (AMS), with particular interest in procedures for small samples, and hence we have changed the title to reflect the focus. Here, we summarize the workshop discussion, adding additional background information and references to publications. Several aspects of graphite preparation are included: catalyst types and ratio of catalyst to carbon; optimal reaction temperatures for various sample sizes; methods for water removal; types of pressure transducers; preconditioning of catalyst; and problems with blank values in very small samples. The pros and cons of sample dilution were also discussed.

\section{THE GRAPHITIZATION REACTION}

Graphite for accelerator mass spectrometry (AMS) measurement is normally produced by reduction of $\mathrm{CO}_{2}$ gas over a catalyst. Ideally, the graphitization reaction will: proceed quickly; go to completion; carbon contamination will be minimized; the catalyst will be easy to handle; the graphite will be easily packed into targets; and the graphite will produce high beam currents in the AMS system. The graphitization reaction is quite complex, and the interplay of a number of factors influence the efficiency of the reaction. Factors include reaction temperature, effectiveness of water removal, catalyst type and amount, reduction method (e.g. hydrogen or zinc), ratio of gases, and total pressure of gases. A number of papers discuss the reaction in detail (McNichol et al. 1992; Gudenau et al. 2005; Němec et al. 2010; and references therein). However, given the complexity of the reaction, it is usually more practical to use empirical methods to determine optimal graphitization conditions for the particular lab and AMS.

\section{CHOICE OF CATALYST}

The choice of catalyst is important to both graphitization and performance in the AMS. Most labs use iron, with cobalt being less commonly used. The workshop discussion was limited to iron catalyst. Important considerations in selecting iron are graphitization speed, contamination in the iron, performance in the AMS, and availability. Iron from chemical suppliers is graded on "purity," but this purity rating relates to contamination from other metals, not from carbon. Thus, different batches of iron, and even different bottles with the same batch number, can have widely differing amounts of carbon in them, and the age of the contaminating carbon may vary. Some batches also have significant amounts of lithium, which is of concern to AMS systems using 2+ or 4+ charge state. The most commonly used iron powder is Alfa Aesar -325 mesh, 98\% purity. Although this product makes graphite that performs well in AMS systems, it is famous for some poor batches, with large amounts of carbon and/or lithium. Several participants stressed the necessity of testing each and every bottle before use, and once a good one is found, buying a lifetime supply of it. Sigma Aldrich -325 mesh is also commonly used, although several participants had less success with this brand. A Japanese supplier made excellent, clean iron, which required no preconditioning, but it is no longer available. Porous iron pellets are another possible choice, but it was noted that these do not

${ }^{1}$ NOAA Earth Systems Research Laboratory, 325 Broadway, Boulder, Colorado 80303, USA. Corresponding author. Email: jocelyn.turnbull@noaa.gov.

${ }^{2}$ Rafter Radiocarbon Laboratory, GNS Science, 30 Gracefield Rd, Lower Hutt, New Zealand.

C 2010 by the Arizona Board of Regents on behalf of the University of Arizona Proceedings of the 20th International Radiocarbon Conference, edited by A J T Jull RADIOCARBON, Vol 52, Nr 2-3, 2010, p 1230-1235 
appear to perform differently than iron powder. Santos et al. (2007) gives an excellent review of performance characteristics of a number of iron powders.

\section{CATALYST TO CARBON RATIOS}

The amount of catalyst used varies between labs, and the optimal choice may be dependent on the particular AMS configuration and the type of catalyst used. Larger amounts of catalyst tend to result in improved ion currents, but the catalyst is also a significant source of contamination, so using less catalyst will improve background values. Of labs using iron powder, most favor using a set amount of iron for all samples, regardless of size; the amount used ranges from $2-5 \mathrm{mg}$ at various labs. This methodology has the benefit that the amount and age of contaminating carbon in the catalyst can be quantified, and a correction applied uniformly to all results. Some groups instead vary the amount of catalyst to maintain a constant $\mathrm{Fe}: \mathrm{C}$ ratio, which may benefit AMS performance in some machines, and reduces contamination from the catalyst, especially for small samples. Again, if the amount of catalyst used is known, a correction can be made for this contamination.

\section{WATER TRAPPING}

In order for the graphitization reaction to proceed to completion, it is essential that the water be removed. The most common method is freezing out of water with either a slush bath or thermoelectric coolers. Chemical absorption of water is also popular. Note that when the reduction is performed with zinc instead of hydrogen, none of these methods are needed.

For water traps, the temperature varies dramatically between labs. Many labs freeze the water at temperatures ranging from $0{ }^{\circ} \mathrm{C}$ to $-40{ }^{\circ} \mathrm{C}$, and find that this is sufficient to drive the reaction to completion, at least for large samples. For small samples, the temperature of the water trap appears to be more critical, with temperatures of $-80^{\circ} \mathrm{C}$ necessary for the reaction to go to completion (e.g. Smith et al. 2007). For very small samples, the reaction typically goes very quickly (20-30 $\mathrm{min}$ ) so it is not difficult to keep an ethanol slush bath cold. Alternatively, if the reaction does not complete, the ethanol slush bath can be refreshed, and the reaction will resume and complete.

Thermoelectric coolers are a popular alternative to slush baths, eliminating the need to prepare and refresh slush baths. It is difficult to achieve temperatures of $-80^{\circ} \mathrm{C}$ with a thermoelectric cooler; instead, they are typically in the range of $0{ }^{\circ} \mathrm{C}$ to $-20^{\circ} \mathrm{C}$. Double-stage coolers can achieve $-40{ }^{\circ} \mathrm{C}$.

Chemical water removal is another option, and the several groups that use it are happy with the results. Magnesium perchlorate $\left(\mathrm{Mg}\left(\mathrm{ClO}_{4}\right)_{2}\right)$ flakes are commonly used. Water trapping is extremely effective, especially for small samples, and it is simple to use. However, a slight difference in oxalic acid standard values was noted when $\mathrm{Mg}\left(\mathrm{ClO}_{4}\right)_{2}$ is used (Santos et al. 2004).

\section{PYREX VERSUS QUARTZ}

Quartz tubes are usually used for the graphitization reaction, since quartz (melting point $1600{ }^{\circ} \mathrm{C}$ ) will not melt at the temperatures used. A number of labs use Pyre ${ }^{\circledR}$ or equivalent materials instead. Pyrex is much cheaper than quartz, has less potential for lithium contamination (lithium is used in the production of quartz; note that low-lithium quartz can be purchased from specialty glassware suppliers), and is less prone to static buildup. However, Pyrex melts at $600{ }^{\circ} \mathrm{C}$, which means that reaction temperatures must stay below this (see section Graphitization Temperature). Most labs do see some warping of the Pyrex tubes during the reaction, but do not observe any contamination problems associated with this. If very high temperatures occur, the tubes can deform enough that the graphite cannot be removed from the tube, so some care must be taken in temperature control. 


\section{STATIC PROBLEMS}

Static can be a problem with graphite and iron. Anti-static guns do not seem to be particularly useful. Magnets can help to move iron, but are not completely successful. Many labs find that storing reaction tubes (both Pyrex and quartz) in a humidified box is the best solution.

\section{GRAPHITIZATION TEMPERATURE}

Early work on graphitization recommended temperatures of $600-650{ }^{\circ} \mathrm{C}$ for graphitization, to ensure complete reaction to graphite (e.g. Vogel et al. 1984; Hut et al. 1986; Arnold et al. 1987; McNichol et al. 1992; Kitagawa et al. 1993; Sie et al. 1994; Aerts-Bijma et al. 1997; Kretschmer et al. 1997; Pearson et al. 1998). However, there is a recent trend to use temperatures as low as $400{ }^{\circ} \mathrm{C}$. Initially, this change was driven by the use of Pyrex reactor tubes, where reaction temperatures of 500 to $570{ }^{\circ} \mathrm{C}$ are used to avoid melting the Pyrex. Many labs have used these temperatures for a number of years, with excellent success. Several groups have more recently determined that for small samples, lower temperatures are more effective, typically 400 or $450{ }^{\circ} \mathrm{C}$, and one lab has used $200{ }^{\circ} \mathrm{C}$. If water is very effectively removed, then small samples will still react well at "standard" reaction temperatures of $550^{\circ} \mathrm{C}$ or above.

It is not clear whether lower temperatures reduce the reaction rate. More importantly, there was concern that at lower temperatures, methane may be produced instead of graphite - after all, this is the desired outcome of preconditioning procedures, which are usually performed at $400{ }^{\circ} \mathrm{C}$. This conclusion is supported by the early literature. However, the lower hydrogen pressure used for small samples seem to be enough to change the reaction conditions and produce graphite rather than methane. Some participants suggested that higher temperatures (over $650^{\circ} \mathrm{C}$ ) are more favorable for producing methane, and it is less of a concern at low temperatures.

It was also noted that even if the furnace temperature is well known, the actual temperature inside the reactor might vary. Thus, the exact temperature chosen is not too critical.

\section{PRESSURE MEASUREMENT}

Many labs monitor the progress of the graphite reaction using pressure transducers inside the reactor. This is by no means universal, with a number of labs simply allowing the reaction to run for a set length of time, and recording only the initial and final pressures. The pressure is also needed to determine sample size, so that the correct amount of hydrogen is added, and for matching standard and sample sizes for small samples. It can, however, be difficult to accurately measure pressure for small samples, and a number of recommended solutions to this problem were suggested. Pressure transducers with a small measurement range (e.g. 0-10 Torr) can be purchased, and the pressure transducer used in the reactor changed depending on the sample size. It is also possible to purchase a single pressure transducer that can switch between different pressure ranges as needed. When recording the sample pressure (and hence, mass), a simpler solution is to have 2 options for the known volume. The pressure transducer is placed inside a small volume, which is used for small samples. For larger samples, a valve can be opened to expand the sample into a larger known volume.

Several types of pressure measurement devices were recommended by workshop participants, including MKS Baratron capacitance manometers and Omega PX176 pressure transducers, both of which are "clean," using stainless steel wetted parts. Two much lower cost options are Silicon Microstructures SM5812 (now made in Europe by AMSYS as AMS5812, US\$25), and Omega PX139 (US\$90), although these both contain some plastic parts that may contribute to a small memory effect (Southon 2007). Entran pressure sensors, designed to measure at low pressures, were 
mentioned as a poor option, being very expensive and prone to drift in the presence of hydrogen. Most of the types listed can be purchased in different measurement ranges as required.

\section{PRECONDITIONING OF CATALYST}

Catalysts typically need to be preconditioned before the graphitization reaction, with 2 aims in mind: removing contaminating carbon from the catalyst and to improve the catalytic properties. The most common preconditioning method for iron is to bake under hydrogen atmosphere for 30-60 min, in an attempt to remove any carbon and/or iron oxides present in the iron (removal of iron oxides should increase the conductivity of the iron powder and potentially speed up the reaction). However, this does not completely remove carbon contamination from the most commonly used types of iron. It was suggested the preconditioning effectiveness may be improved if the water is also removed.

Some groups precondition the iron by first oxidizing and then reducing under hydrogen. Others are concerned that although this should result in cleaner iron, it may sinter, reducing the catalytic properties and/or making it difficult to pack into targets. It was also questioned as to how thorough the oxidation step is, and whether the oxidation might only occur on the surface of the iron.

Of the groups using the oxidizing step, several different methods are used: one group oxidizes in air, whereas others use pure oxygen, typically at $400-500{ }^{\circ} \mathrm{C}$ for $15-30 \mathrm{~min}$. The hydrogen reduction step is then performed at temperatures ranging from $500-620^{\circ} \mathrm{C}$ for $30-60 \mathrm{~min}$. If the reduction temperature is too high, then sintering can occur. Hua et al. (2004) compared different preconditioning methods (using Cerac -400 mesh iron powder), and found that including the oxidation step did not improve background values, although it did improve the reaction rate. Unfortunately, it was also more difficult to press into the targets. They also observed that Sigma Aldrich -400 mesh iron powder sintered if oxidation was performed.

\section{SPECIAL CONSIDERATIONS FOR SMALL SAMPLES}

Small samples require special attention, and background contamination is of particular concern. Several participants argued that the main source of contamination is in the catalyst, and that by carefully quantifying the amount and age of the contaminant, it can be corrected for. Most labs find that it is important to make and measure standard materials of the same size as each small sample. Others postulated that the background contamination is an AMS measurement effect. When the ion current is very low, the Faraday cups do not work as well, unless they are very carefully calibrated. Hence, the data are not usually reliable for low currents, and some labs simply discard data when the ion current drops below a threshold value.

\section{SAMPLE DILUTION}

For batches of very small samples that vary in size, it could be beneficial to dilute, making them a consistent size. This allows use of standards and blanks of one size, rather than making a suite of standards and blanks to match the sample size range. A number of people have experimented with this for natural ${ }^{14} \mathrm{C}$ samples. The major problem appears to be accurately determining the amount of dilutant added, and its ${ }^{14} \mathrm{C}$ content must also be known. Although the AMS measurement statistical uncertainty may be lower for the larger, diluted sample, when uncertainty in the amount and age of dilutant is included, the overall precision is comparable to that from the smaller, undiluted sample. There are also practical issues in adding the dilutant, which may make it less desirable. Nevertheless, dilution may be a preferred option to analyzing very small samples. Dilution is commonly used 
for large biomedical samples, to bring the ${ }^{14} \mathrm{C}$ content down before measurement, but similar issues are encountered for small biomedical samples.

\section{ZINC REDUCTION METHOD}

Although reduction with hydrogen and trapping of water is the most common graphitization method, a number of labs use the "zinc method" (Slota et al. 1987; Vogel 1992; Xu et al. 2007). It is often assumed that this method is not as clean as the hydrogen method, but recent advances suggest that similar precision can be achieved. Some fractionation occurs (e.g. Jull et al. 1986), and must be corrected for; this is easily achieved when an AMS that measures $\delta^{13} \mathrm{C}$ online is used. Rarely, a crust can form on the iron powder catalyst that stops the reaction. This only happens for very large samples, and very rarely. The problem can be solved by tapping the tube, but participants in the workshop were not able to suggest a reason for this.

\section{CONCLUSIONS}

It is difficult to summarize a workshop that represented more of an exchange of information and comparison of procedures than a concerted effort to solve specific problems. Some observations can be made, however. First, there is a surprising degree of variation among AMS laboratories using the same basic method for graphitization, i.e. hydrogen reduction over an iron catalyst. Laboratories differ in everything from the type of glass the reaction tubes are made from, the type of catalyst used, the ratio of catalyst, how water is trapped, the temperature of the reaction, to how they determine when the reaction is complete. The choice of operating condition determines the rate and efficiency of the graphite reaction, the amount of contamination in the graphite produced, and the current the graphite produces in the AMS. It was noted more than once that choices for specific parameters are often made to suit the peculiarities of a particular AMS or vacuum line. It was also observed that all of the factors are interconnected; that a change in water trap might improve the efficiency of the reaction, but affect the rate, or that a factor that increases the rate of the reaction might also increase the background values. Thus, there is no single correct procedure but simply a process of experimentation and observation ... and exchange of ideas between laboratories.

The workshop, although short, created a lively discussion of procedural details, particularly for graphitization. Although not discussed in depth during this session, topics such as contamination, corrections for contamination, memory effects, and fractionation were alluded to during the conversation and would clearly present fruitful material for future consideration. We hope to convene a longer such workshop, with time to discuss other aspects of sample preparation, possibly at the 21 st International Radiocarbon conference in 2012.

Thanks to all the participants and to the conference organizers who helped the workshop to happen.

\section{REFERENCES}

Aerts-Bijma A, Meijer HAJ, van der Plicht J. 1997. AMS sample handling in Groningen. Nuclear Instruments and Methods in Physics Research B 123(1-4): 221-5.

Arnold M, Bard E, Maurice P, Duplessy J-C. $1987 .{ }^{14} \mathrm{C}$ dating with the Gif-sur-Yvette Tandetron accelerator: status report. Nuclear Instruments and Methods in Physics Research B 29(1-2):120-3.

Gudenau HW, Senk D, Wang S, De Melo Martins K, Stephany C. 2005. Research in the reduction of iron ore agglomerates including coal and C-containing dust. ISIJ International 45(4):603-8.

Hua Q, Zoppi U, Williams A, Smith AM. 2004. Smallmass AMS radiocarbon analysis at ANTARES. $\mathrm{Nu}$ clear Instruments and Methods in Physics Research B 223-224:284-92.

Hut G, Göte Östlund H, Van der Borg K. 1986. Fast and complete $\mathrm{CO}_{2}$-to-graphite conversion for ${ }^{14} \mathrm{C}$ accelerator mass spectrometry. Radiocarbon 28(2A): 186-90. Jull AT, Donahue DJ, Gore B, Hatheway A, Linick T, Da- 
mon PE. 1986. Recent developments in AMS ${ }^{14} \mathrm{C}$ dating using the Arizona Facility. In: Workshop on Techniques in Accelerator Mass Spectrometry. Oxford. p 14-22.

Kitigawa H, Masuzawa T, Makamura T, Matsumoto E. 1993. A batch preparation method for graphite targets with low background for AMS ${ }^{14} \mathrm{C}$ measurements. $\mathrm{Ra}$ diocarbon 35(2):295-300.

Kretschmer W, Anton G, Bergmann M, Finckh E, Kowalzik B, Klein M, Leigart M, Merz S, Morgenroth G, Piringer I. 1997. The Erlangen AMS facility: status report and research program. Nuclear Instruments and Methods in Physics Research B 123(1-4):93-6.

McNichol AP, Gagnon AR, Jones GA, Osborne EA. 1992. Illumination of a black box: analysis of gas composition during graphite target preparation. $R a$ diocarbon 34(3):321-9.

Němec M, Wacker L, Gäggeler H. 2010. Optimization of the automated graphitization system AGE-1. Radiocarbon 52(2-3):1380-93.

Pearson A, McNichol AP, Schneider RJ, von Reden KF, Zheng Y. 1998. Microscale AMS ${ }^{14} \mathrm{C}$ measurement at NOSAMS. Radiocarbon 40(1):61-75.

Santos G, Southon JR, Druffel-Rodriguez KC, Griffin S, Mazon M. 2004. Magnesium perchlorate as an alternative water trap in AMS graphite sample preparation: a report on sample preparation at KCCAMS, University of California, Irvine. Radiocarbon 46(1):165-73.

Santos GM, Mazon M, Southon JR, Rifai S, Moore R. 2007. Evaluation of iron and cobalt powders as cata- lysts for ${ }^{14} \mathrm{C}$-AMS target preparation. Nuclear Instruments and Methods in Physics Research B 259(1): 308-15.

Sie SH, Leaney F, Gillespie R, Suter GF, Ryan CG. 1994. Radiocarbon measurements at the CSIRO AMS facility. Nuclear Instruments and Methods in Physics Research $B$ 92(1-4):35-8.

Slota Jr PJ, Jull AJT, Linick TW, Toolin LJ. 1987. Preparation of small samples for ${ }^{14} \mathrm{C}$ accelerator targets by catalytic reduction of CO. Radiocarbon 29(2):303-6.

Smith AM, Petrenko VV, Hua Q, Southon JR, Brailsford G. 2007. The effect of $\mathrm{N}_{2} \mathrm{O}$, catalyst, and means of water vapor removal on the graphitization of small $\mathrm{CO}_{2}$ samples. Radiocarbon 49(2):245-54.

Southon JR. 2007. Graphite reactor memory-Where is it from and how to minimize it? Nuclear Instruments and Methods in Physics Research B 259(1):288-92.

Vogel JS. 1992. Rapid production of graphite without contamination for biomedical AMS. Radiocarbon 34(3):344-50.

Vogel JS, Southon JR, Nelson DE, Brown TA. 1984. Performance of catalytically condensed carbon for use in accelerator mass spectrometry. Nuclear Instruments and Methods in Physics Research B 5(2):289-93.

Xu X, Trumbore SE, Zheng S, Southon JR, McDuffee KE, Luttgen M, Liu JC. 2007. Modifying a sealed tube zinc reduction method for preparation of AMS graphite targets: reducing background and attaining high precision. Nuclear Instruments and Methods in Physics Research B 259(1):320-9. 